\title{
Review Article \\ Green Tea Catechins: Their Use in Treating and Preventing Infectious Diseases
}

\author{
Wanda C. Reygaert (i) \\ Biomedical Sciences Department, Oakland University William Beaumont School of Medicine, Rochester, MI 48309, USA \\ Correspondence should be addressed to Wanda C. Reygaert; reygaert@oakland.edu
}

Received 20 March 2018; Accepted 10 June 2018; Published 17 July 2018

Academic Editor: Chedly Chouchani

Copyright (C) 2018 Wanda C. Reygaert. This is an open access article distributed under the Creative Commons Attribution License, which permits unrestricted use, distribution, and reproduction in any medium, provided the original work is properly cited.

Green tea is one of the most popular drinks consumed worldwide. Produced mainly in Asian countries from the leaves of the Camellia sinensis plant, the potential health benefits have been widely studied. Recently, researchers have studied the ability of green tea to eradicate infectious agents and the ability to actually prevent infections. The important components in green tea that show antimicrobial properties are the catechins. The four main catechins that occur in green tea are (-)-epicatechin (EC), (-)epicatechin-3-gallate (ECG), (-)-epigallocatechin (EGC), and (-)-epigallocatechin-3-gallate (EGCG). Of these catechins, EGCG and EGC are found in the highest amounts in green tea and have been the subject of most of the studies. These catechins have been shown to demonstrate a variety of antimicrobial properties, both to organisms affected and in mechanisms used. Consumption of green tea has been shown to distribute these compounds and/or their metabolites throughout the body, which allows for not only the possibility of treatment of infections but also the prevention of infections.

\section{Introduction}

Infectious diseases are a leading cause of morbidity and mortality worldwide. HIV/AIDS and malaria are among the top ten infectious diseases in the world; and the most common types of infections are respiratory tract and diarrheal diseases [1]. With the advent of antimicrobial agents in the mid-1900s came the hope that eradication of infectious diseases was close. Unfortunately, the microorganisms involved were able to become resistant to the antimicrobial agents, and that only made it harder to fight these organisms. The CDC has estimated that each year more than two million people in the US suffer from antibiotic-resistant infections and that as many as 23,000 people die each year from these infections [2]. This results in not only increased morbidity and mortality, but also increased healthcare costs, which can be a huge financial burden for many countries. A recent analysis of the medical costs from healthcare-associated infections (those infections acquired in a healthcare facility) alone estimated that the annual costs of these infections in the US are between 28 and 45 billion dollars [3]. Antimicrobial resistance issues continue to impact these costs. One study found that the cost of antimicrobial resistance associated illnesses in the US could be as high as 55 billion dollars (20 billion dollars for healthcare costs and 35 billion dollars for lost productivity) annually [4]. To help in the fight against infectious diseases, researchers are looking at the possibilities of using natural plant products, which could turn out to provide a tremendous cost savings in healthcare. One of the plants that is currently being widely studied is the tea plant, looking especially at green tea.

Tea is one of the most commonly consumed beverages in the world, and green tea is becoming increasingly popular, accounting for around $20 \%$ of total global tea production. Tea is produced from the Camellia sinensis plant and is grown in over 30 countries. The best areas for growing tea plants are in specific tropical and subtropical regions. There are four main tea types produced: white, green, Oolong, and black tea. The type of tea is determined by how the tea leaves are processed, specifically by drying and fermentation methods. White tea is processed the least and uses very young leaves and leaf buds. Green tea is produced from more mature leaves with no fermentation. Oolong tea is produced by partially fermenting the leaves and black tea by fully fermenting the leaves [5-7]. Green tea is most commonly consumed in China, Japan, and Korea. Black tea is most commonly consumed in the US and the UK [8]. 
Green tea has been shown to have anticarcinogenic, antiinflammatory, antimicrobial, and antioxidant properties and is beneficial in cardiovascular disease (CVD), diabetes and obesity, and neurologic and oral health. The anticarcinogenic properties include controlling cell proliferation, apoptosis and angiogenesis in tumor cells [9-12]. Inflammation is a component of many conditions and diseases including aging, arthritis, cancer, CVD, diabetes, and obesity. The general anti-inflammatory properties of green tea include the ability to decrease the denaturation of proteins and increase the production of anti-inflammatory cytokines [7, 13]. Oxidative stress results from the damaging effects of reactive oxygen species (ROS). The antioxidant properties of green tea include the ability to limit the amount of free radicals by binding to ROS, upregulating basal levels of antioxidant enzymes, and increasing the activity of these antioxidant enzymes $[6,14,15]$. The effects of green tea on CVD include the anti-inflammatory and antioxidant effects. In addition, the consumption of green tea has been shown to inhibit atherosclerosis, reduce total lipid levels, and improve the ratio of LDL to HDL $[16,17]$. Diabetes and obesity are closely associated with a spectrum of disorders known as metabolic syndrome (MetS) which includes increased waist diameter, elevated plasma triglycerides, decreased HDL, increased fasting blood glucose, and elevated blood pressure [18, 19]. Type 2 diabetes is also associated with insulin resistance and sometimes decreased insulin production. Green tea has been shown to increase insulin receptor sensitivity and stimulate glucose-induced insulin secretion $[20,21]$. Obesity is a result of an increase in fat mass which is caused by increase in the size of fat cells. Green tea has been shown to inhibit digestive enzymes and absorption of fat, which leads to decreased body waist circumference, intra-abdominal fat, plasma total and LDL cholesterol, triglycerides, and blood pressure [2224]. The challenges of inflammation and oxidative stress can lead to DNA damage, protein misfolding, and loss of ATP production in mitochondria. This can result in cell death and loss of cognitive functions in the brain. The antiinflammatory and antioxidant properties of green tea also protect neurons, and green tea metabolites have been shown to cross the blood brain barrier [25-29]. Green tea has been shown to be antimicrobial against most oral bacteria. In addition, it has been shown to improve oral health by increasing the activity of oral peroxidases, preventing the development and progression of periodontitis, and reducing dentin erosion and tooth loss, and it has a role in improving bad breath [30-34].

\section{Green Tea Composition}

The components in green tea that are the most medically relevant are the polyphenols. The most pertinent polyphenols are the flavonoids; and the most pertinent flavonoids are the catechins. The catechins comprise $80-90 \%$ of the flavonoids and around $40 \%$ of the water-soluble solids in green tea. Green tea contains more catechins than the other teas, mainly because of the way it is processed after harvesting. The amount of catechins in green tea can also be affected by where the tea is grown, the growth conditions, when it is harvested, how the leaves are processed, and the brewing temperature and length of time of brewing. These factors lead to a huge variation in catechin content among the varieties and brands of green tea consumed [35-45].

The four main catechins found in green tea are (-)-epicatechin (EC), (-)-epigallocatechin (EGC), (-)epicatechin-3-gallate (ECG), and (-)-epigallocatechin-3gallate (EGCG). The most abundant catechin is EGCG ( $\sim 60 \%)$, and the next most abundant is EGC $(\sim 20 \%)$, then ECG $(\sim 14 \%)$, and EC ( $6 \%)$. EGCG is the most studied in association with health, but EGC and ECG have been studied as well. As mentioned above, there can be a wide variation in the amount of catechins in any particular green tea beverage, although standardized extracts are available for use as supplements [7, 46, 47].

In order to be effective in the body these catechins need to be bioavailable after consumption. Once in the body, the catechins undergo metabolic processing in the liver and small intestine and colon. This processing produces glucuronide and sulfate conjugates or methyl epicatechins. Native forms of ECG and EGCG and metabolites of EC and EGC can be detected and measured in blood plasma. No forms of ECG and EGCG can be detected in urine, only metabolites of EC and EGC $[48,49]$. Catechins are generally most stable in solution at a $\mathrm{pH}$ range of 4-6. It is now known that human serum albumin acts as a stabilizer, binding to the catechins and then transporting them [50]. Various studies in humans have found that the peak concentrations of catechins and their metabolites occur in blood plasma between 1.5 and 2 hours after ingestion and in urine between 4 and 6 hours after ingestion. The levels of these peak concentrations are affected by an individual's metabolism and of course by the amount of catechins in the ingested type of green tea. Commonly, the levels found in the body are directly proportional to the amount of catechins consumed [51-53]. Tables 1 and 2 show examples of blood plasma and urine concentration studies in humans.

\section{Antimicrobial Properties}

The antimicrobial effects of green tea catechins (GTCs) on microorganisms have been studied for many years. Green tea has been shown to combat these organisms in various ways, directly and indirectly, and has been shown to work synergistically with some antibiotic agents. Other known health benefits of green tea such as the anti-inflammatory and antioxidant effects may also contribute to the antimicrobial effects. Studies conducted on Escherichia coli found that exposure to green tea polyphenols (GTPs) resulted in major gene expression changes for 17 genes, with upregulation occurring in nine genes and downregulation in eight genes [75-77]. Table 3 shows a summary of the antimicrobial effects of green tea on bacteria.

\section{Effects on the Bacteria Cell Membrane}

One of the major properties of GTCs is the ability to bind to bacterial cell membranes. This binding can lead to interference in various bacterial processes and can damage the cell 
TABLE 1: Amount of EGCG in blood plasma after a single dose.

\begin{tabular}{lcc}
\hline EGCG dose $(\mathrm{mg})$ & $\mathrm{C}_{\max }(\mathrm{ng} / \mathrm{ml})$ & Reference \\
\hline 200 & 73.7 & {$[54]$} \\
400 & 111.8 & \\
600 & 169.1 & \\
800 & 438.5 & {$[55]$} \\
\hline 400 & 137.6 & {$[56]$} \\
800 & 234.9 & {$[57]$} \\
\hline 88 & 135 & {$[58]$} \\
140 & 34.7 & {$[59]$} \\
\hline 225 & 300 & \\
375 & 1970 & \\
525 & 2020 & \\
\hline 50 & 130.4 & \\
100 & 180.4 & \\
200 & 332.2 & \\
400 & 624.5 & \\
800 & 1067.4 & \\
1600 & 3391.6 & \\
\hline 200 & 376.9 & \\
400 & 525.2 & \\
800 & 1682.1 & \\
\hline 110 & 119 & \\
219 & 326 & \\
329 & 321 & \\
\hline
\end{tabular}

TABLE 2: Amount of EGC in 24-hour urine collection.

\begin{tabular}{lcc}
\hline EGC dose $(\mathrm{mg})$ & Amount in 24 hour urine $(\mathrm{mg})$ & Reference \\
\hline 37 & 0.4 & {$[54]$} \\
74 & 1.4 & \\
111 & 3.5 & \\
148 & 3.7 & {$[56]$} \\
\hline 82 & $\sim 3.0$ & {$[57]$} \\
154 & 3.5 & {$[62]$} \\
148 & 10.5 & {$[61]$} \\
102 & $\sim 3.0$ & \\
204 & $\sim 4.0$ & \\
306 & $\sim 4.8$ & \\
\hline
\end{tabular}

membrane resulting in increased permeability and leading to cell lysis. Because EGCG is negatively charged it can combine with the positively charged bacterial cell membrane, especially in gram positive bacteria. The lipopolysaccharide (LPS) on the outer membrane of gram negative bacteria makes them more resistant to binding by GTCs $[53,63,64,66]$. Studies with E. coli and Pseudomonas aeruginosa have shown that EGCG binding to the bacterial cell membrane can result in generation of $\mathrm{H}_{2} \mathrm{O}_{2}$ which is involved in damage to the cell membrane $[63,74]$. Studies with Staphylococcus aureus have shown that this assault on the cell membrane causes a major cell wall stress response, resulting in upregulation of peptidoglycan biosynthesis genes and an alteration in cell wall structure. In methicillin-resistant Staphylococcus aureus
(MRSA) strains, this change in peptidoglycan biosynthesis genes results in the production of PBP2 (penicillin-binding protein 2), which is what confers resistance to $\beta$-lactam drugs. Production of PBP2 is also inhibited by EGCG [64, $78,79]$. An important result of green tea binding is the loss of bacterial ability to bind to host cells. Studies using human and mammalian cells lines have shown that various bacteria such as Fusobacterium nucleatum, Staphylococcus epidermidis, and Helicobacter pylori have significantly decreased adherence to these cells $[66,67,80]$. Other important results are the loss of the ability for quorum sensing and biofilm formation of P. aeruginosa, F. nucleatum, and Streptococcus mutans [66, $68,81]$. Damage to the cell membrane also results in loss of function to transmembrane transporter proteins which are responsible for secretion of toxins and efflux of substances such as antimicrobial agents $[53,65,69,70]$.

\section{Effects on Other Bacterial Cell Functions}

There are a wide variety of other effects that GTCs have on bacterial functions. An important one which can affect most bacteria is the ability of GTCs to inhibit bacterial fatty acid biosynthesis by inhibiting enzymes involved in the biosynthetic pathway. Because this is an essential pathway for most bacteria, researchers are looking at targeting this pathway in antimicrobial drug development. Fatty acids are important for building cell membranes, as an energy source, and are involved in the production of toxic bacterial metabolites $[53,73]$. Another target is the folate biosynthesis pathway. The enzyme dihydrofolate reductase (DHFR) is essential in this pathway, and is known to be a target for certain sulfa drugs. EGCG has also been shown to inhibit DHFR activity $[53,82]$. Other important effects against enzymes include inhibition of bacterial DNA gyrase, inhibition of bacterial ATP synthase activity, and inhibition of bacterial protein tyrosine phosphatase and cysteine proteases [53, 71, 83]. Some specific bacterial effects include reducing bacterial $\mathrm{H}_{2} \mathrm{~S}$ production and inhibiting hemolytic activity of F. nucleatum, inhibiting the ability of Listeria monocytogenes to escape from the macrophage phagosome by inhibiting activity of listeriolysin $\mathrm{O}$, and inhibiting the ability of E. coli to transfer plasmid content via conjugation $[66,72,84]$.

\section{Synergism}

Since GTCs are known to have antimicrobial action, researchers have begun assessing the potential synergism of these catechins with other known antimicrobial agents. Green tea catechins have now been shown to act in synergy with imipenem against MRSA; with metronidazole against Porphyromonas gingivalis; with azithromycin, cefepime, ciprofloxacin, chloramphenicol, doxycycline, erythromycin, nalidixic acid, piperacillin, or tobramycin against E. coli; with ampicillin, Cefalotin, doxycycline, erythromycin, penicillin, or tetracycline against Enterobacter aerogenes; with chloramphenicol or tetracycline against Pseudomonas aeruginosa; and with aztreonam, ceftazidime, ciprofloxacin, gentamicin, meropenem, or tetracycline against Acinetobacter baumannii. The ability of GTCs to inhibit the function of 
TABLE 3: Antimicrobial effects of green tea catechins.

\begin{tabular}{|c|c|c|}
\hline Organism & Effects & References \\
\hline Cell Membrane & Binding to bacterial cell membrane & {$[63-65]$} \\
\hline \multirow[t]{5}{*}{ Associated Effects } & Damaging bacterial cell membrane & [63] \\
\hline & Inhibits ability of bacteria to bind to host cells & {$[66,67]$} \\
\hline & Inhibits ability of bacteria to form biofilms & {$[66,68,69]$} \\
\hline & Disrupts bacterial quorum sensing & [68] \\
\hline & Interferes with bacterial membrane transporters & {$[65,69,70]$} \\
\hline Bacterial Cell Functions & Inhibits bacterial DNA gyrase & {$[71]$} \\
\hline \multirow[t]{5}{*}{ Effects } & Reduces bacterial $\mathrm{H}_{2} \mathrm{~S}$ production & {$[66]$} \\
\hline & Inhibits bacterial hemolytic action & {$[66,72]$} \\
\hline & Inhibition of bacterial DHFR enzyme & {$[53]$} \\
\hline & Inhibits bacterial fatty acid synthesis enzymes & {$[73]$} \\
\hline & Increases bacterial internal ROS levels & {$[74]$} \\
\hline
\end{tabular}

TABLE 4: Synergism of green tea with antimicrobial agents.

\begin{tabular}{lc}
\hline Antimicrobial Action & Drug Synergism \\
\hline Inhibit Cell Wall Synthesis & ampicillin \\
ampicillin/sulbactam & amoxicillin \\
aztreonam & cefalotin \\
cefepime & cefotaxime \\
ceftazidime & imipenem \\
meropenem \\
oxacillin \\
penicillin \\
piperacillin \\
\hline Inhibit Protein Synthesis & amikacin \\
& azithromycin \\
chloramphenicol & doxycycline \\
erythromycin & gentamicin \\
tetracycline & tobramycin \\
\hline & ciprofloxacin \\
levofloxacin \\
metronidazole \\
nalidixic acid \\
\hline
\end{tabular}

bacterial efflux pumps (as mentioned previously) also plays a role in at least an additive antimicrobial effect for GTCs and many antimicrobial drugs, especially in gram negative bacteria that possess RND-type efflux pumps [53, 69, 70, 85-89]. Table 4 lists antimicrobial agents that have shown synergy with GTCs and the targets of these drugs.

\section{Effects on Other Microorganisms}

Green tea catechins have also been shown to be effective against a number of viruses, parasites, fungi, and even prions. The main antiviral effects include inhibiting the virus from binding to and entering host cells (adenovirus, enterovirus, HBV, HCV, HIV, HSV, influenza, and rotavirus); inhibiting viral RNA and DNA synthesis and viral gene transcription (enterovirus, EBV, HBV, HCV, and HIV); and destroying and functionally altering various viral molecules (adenovirus, HSV, and influenza) [64, 90-96]. Studies performed with adult healthcare workers to determine if green tea supplements could prevent infection with viruses causing influenza showed significantly fewer instances of influenza symptoms and a reduced incidence of laboratory-confirmed influenza cases versus the control group [97].

The main effect of GTCs on various parasite infections is a decrease in parasite numbers and growth. Other effects noted were fragmentation of parasite DNA and reduced fatty acid synthesis in the parasites. Studies with parasites include Plasmodium falciparum, Babesia spp., Trypanosoma brucei, Trypanosoma cruzi, and Leishmania braziliensis [98-102].

Fungi that have been affected by GTCs include Aspergillus niger, Candida spp., Penicillium sp., Microsporum canis, Trichophyton mentagrophytes, and Trichophyton rubrum. Research testing for synergistic effects found that EGCG showed synergism with amphotericin B, fluconazole, and miconazole in Candida spp.; and in Candida tropicalis strains that were resistant to fluconazole, EGCG, and fluconazole together induced apoptosis in the yeast cells [64, 103-107].

Prions are proteins that are considered to be infective agents because the abnormally structured ( $\beta$-sheet) forms are able to induce normally structured ( $\alpha$-helix) forms to change shape. In the abnormal shape, protein function is lost and protein aggregation occurs in cells. Unlike other infectious agents, prions cannot be destroyed using autoclaving; the proteins have to be degraded to be noninfectious. Research using yeast cells found that EGCG could inhibit the $\beta$-sheet prions from changing the $\alpha$-helical forms and could induce reversal of the $\beta$-sheet forms back to $\alpha$-helical forms [108]. 


\section{Antimicrobial Scope}

There is a large amount of research that has assessed the antimicrobial effects of green tea catechins on a wide variety of microorganisms, including many gram negative and gram positive bacteria, some viruses, fungi, and prions. One of the most clinically important bacteria that has been researched is S. aureus, especially MRSA strains. The most studied gram negative bacteria is $E$. coli which is known for causing the majority of urinary tract infections. There are several recently published manuscripts that contain extensive information on which organisms are affected by green tea catechins $[53,64$, 96, 109].

\section{Prevention of Infection}

Since it has been shown that GTCs have multiple types of antimicrobial abilities against so many organisms, it would be expected that green tea catechins could also prevent infections. One study was mentioned previously describing how green tea reduced the number of colds and influenza incidents. Another study involving adults showed that consuming green tea supplements twice daily for 3 months resulted in $32 \%$ fewer instances of cold or influenza symptoms and nearly $23 \%$ fewer illnesses of 2 or more days duration [110]. A study involving children found that, in schoolaged children who consumed green tea on a regular basis, the number of incidents of influenza A or B was inversely associated with the number of cups of green tea consumed per day or per week [111]. Another study with Japanese nursey school children who gargled with green tea (or placebos) at least once each day found that there were up to 3 times fewer instances of illnesses with fevers in the green tea gargling group [112]. Two other studies with adults found that gargling with a green tea extract (GTE) solution resulted in at least half as many cases of influenza in the GTE gargling groups compared with the control groups $[113,114]$.

\section{Conclusions}

The research into the effects of green tea on human health has shown that it can be an important dietary factor in the prevention and treatment of various diseases such as arthritis, cancer, CVD, diabetes and obesity, infections, and in neurologic and oral health. Studies that were originally performed in animals and cell lines have become more frequently performed using humans. This type of research is vital if we are to fully discover what benefits GTCs can have in health issues. The more researchers that become involved in this, the clearer the answers. The studies on antimicrobial effects are providing very promising data, especially if GTCs prove to have synergistic abilities with many of the currently used antimicrobial agents and perhaps with drugs used to treat other diseases. The emergence of various multidrug-resistant bacteria, along with a dearth of effective antimicrobial drugs, makes the potential of green tea an extremely timely issue. There are also many areas across the globe where the cost of drugs is currently beyond the earning power of most of the population. Green tea is relatively inexpensive and fairly easy to obtain for most people. It could prove to be an answer for improving health on a global scale.

\section{Conflicts of Interest}

The author declares that there are no conflicts of interest regarding the publication of this paper.

\section{References}

[1] World Health Organization, "World Health Organization," 2014.

[2] U.S. Department of Health and Human Services Centers for Disease Control and Prevention. "Antibiotic resistance threats in the United States" 2013.

[3] P. W. Stone, "Economic burden of healthcare-associated infections: An American perspective," Expert Review of Pharmacoeconomics \& Outcomes Research, vol. 9, no. 5, pp. 417-422, 2009.

[4] R. Smith and J. Coast, "The true cost of antimicrobial resistance," BMJ, vol. 346, no. 7899, Article ID f1493, 2013.

[5] D. Botten, G. Fugallo, F. Fraternali, and C. Molteni, "Structural Properties of Green Tea Catechins," The Journal of Physical Chemistry B, vol. 119, no. 40, pp. 12860-12867, 2015.

[6] D. A. Gupta, D. J. Bhaskar, and R. K. Gupta, "Green tea: a review on its natural anti-oxidant therapy and cariostatic benefits," Biological Sciences and Pharmaceutical Research, vol. 2, pp. 8$12,2014$.

[7] A. Jigisha, R. Nishant, K. Navin et al., "Green tea: a magical herb with miraculous outcomes," International Research Journal of Pharmacy, vol. 3, no. 5, pp. 139-148, 2012.

[8] K. Hayat, H. Iqbal, U. Malik, U. Bilal, and S. Mushtaq, "Tea and its consumption: benefits and risks," Critical Reviews in Food Science and Nutrition, vol. 55, no. 7, pp. 939-954, 2015.

[9] K. D. Crew, K. A. Ho, P. Brown et al., "Effects of a green tea extract, Polyphenon E, on systemic biomarkers of growth factor signalling in women with hormone receptor-negative breast cancer," Journal of Human Nutrition and Dietetics, vol. 28, no. 3, pp. 272-282, 2015.

[10] M.-J. Li, Y.-C. Yin, J. Wang, and Y.-F. Jiang, "Green tea compounds in breast cancer prevention and treatment," World Journal of Clinical Oncology, vol. 5, no. 3, pp. 520-528, 2014.

[11] Y. Shirakami, H. Sakai, T. Kochi, M. Seishima, and M. Shimizu, "Catechins and its role in chronic diseases," Advances in Experimental Medicine and Biology, vol. 929, pp. 67-90, 2016.

[12] C. Subramani and R. K. Natesh, "Molecular mechanisms and biological implications of green tea polyphenol, (-)epigallocatechin-3-gallate," International Journal of Pharma Bioscience and Technology, vol. 1, no. 2, pp. 54-63, 2013.

[13] P. Chaterjee, S. Chandra, P. Dey et al., "Evaluation of antiinflammatory effects of green tea and black tea: a comparative in vitro study," Journal of Advanced Pharmaceutical Technology \& Research, vol. 3, no. 2, pp. 136-138, 2012.

[14] B. J. Newsome, M. C. Petriello, S. G. Han et al., "Green tea diet decreases PCB 126-induced oxidative stress in mice by up-regulating antioxidant enzymes," The Journal of Nutritional Biochemistry, vol. 25, no. 2, pp. 126-135, 2014.

[15] C. Tsai, Y. Hsu, H. Ting, C. Huang, and C. Yen, "The in vivo antioxidant and antifibrotic properties of green tea (Camellia sinensis, Theaceae)," Food Chemistry, vol. 136, no. 3-4, pp. 13371344, 2013. 
[16] P. Bhardwaj and D. Khanna, "Green tea catechins: defensive role in cardiovascular disorders," Chinese Journal of Natural Medicines, vol. 11, no. 4, pp. 345-353, 2013.

[17] M. A. Islam, "Cardiovascular effects of green tea catechins: Progress and promise," Recent Patents on Cardiovascular Drug Discovery, vol. 7, no. 2, pp. 88-99, 2012.

[18] G. Grandl and C. Wolfrum, "Hemostasis, endothelial stress, inflammation, and the metabolic syndrome," Seminars in Immunopathology, vol. 40, no. 2, pp. 215-224, 2018.

[19] J. Iqbal, A. Al Qarni, A. Hawwari, A. . Alghanem, and A. Gasmelseed, "Metabolic syndrome, dyslipidemia and regulation of lipoprotein metabolism," Current Diabetes Reviews, vol. 13, 2017.

[20] Q. Fu, Q. Li, X. Lin et al., "Antidiabetic Effects of Tea," Molecules, vol. 22, no. 5, p. 849, 2017.

[21] K. M. Munir, S. Chandrasekaran, F. Gao, and M. J. Quon, "Mechanisms for food polyphenols to ameliorate insulin resistance and endothelial dysfunction: therapeutic implications for diabetes and its cardiovascular complications," American Journal of Physiology-Endocrinology and Metabolism, vol. 305, no. 6, pp. E679-E686, 2013.

[22] J. Huang, Y. Wang, Z. Xie, Y. Zhou, Y. Zhang, and X. Wan, "The anti-obesity effects of green tea in human intervention and basic molecular studies," European Journal of Clinical Nutrition, vol. 68, no. 10, pp. 1075-1087, 2014.

[23] N. Siriwardhana, N. S. Kalupahana, M. Cekanova, M. LeMieux, B. Greer, and N. Moustaid-Moussa, "Modulation of adipose tissue inflammation by bioactive food compounds," The Journal of Nutritional Biochemistry, vol. 24, no. 4, pp. 613-623, 2013.

[24] T. Suzuki, M. Pervin, S. Goto, M. Isemura, and Y. Nakamura, "Beneficial effects of tea and the green tea catechin epigallocatechin-3-gallate on obesity," Molecules, vol. 21, no. 10, 2016.

[25] A. Faria, D. Pestana, D. Teixeira et al., "Insights into the putative catechin and epicatechin transport across blood-brain barrier," Food \& Function, vol. 2, no. 1, pp. 39-44, 2011.

[26] I. Figueira, G. Garcia, R. C. Pimpão et al., "Polyphenols journey through blood-brain barrier towards neuronal protection," Scientific Reports, vol. 7, no. 1, article 11456, 2017.

[27] E. Mancini, C. Beglinger, J. Drewe, D. Zanchi, U. E. Lang, and S. Borgwardt, "Green tea effects on cognition, mood and human brain function: A systematic review," Phytomedicine, vol. 34, pp. 26-37, 2017.

[28] A. Scholey, L. A. Downey, and J. Ciorciari, "Acute neurocognitive effects of epigallocatechin gallate (EGCG)," Appetite, vol. 58, no. 2, pp. 767-770, 2012.

[29] D. Vauzour, "Dietary polyphenols as modulators of brain functions: biological actions and molecular mechanisms underpinning their beneficial effects," Oxidative Medicine and Cellular Longevity, vol. 2012, Article ID 914273, 16 pages, 2012.

[30] A. Araghizadeh, J. Kohanteb, and M. M. Fani, "Inhibitory activity of green tea (Camellia sinensis) extract on some clinically isolated cariogenic and periodontopathic bacteria," Medical Principles and Practice, vol. 22, no. 4, pp. 368-372, 2013.

[31] B. U. Aylikci and H. Çolak, "Halitosis: from diagnosis to management," Journal of Natural Science, Biology and Medicine, vol. 4, no. 1, pp. 14-23, 2013.

[32] M. D. R. De Moraes, J. R. M. Carneiro, V. F. Passos, and S. L. Santiago, "Effect of green tea as a protective measure against dental erosion in coronary dentine," Brazilian Oral Research, vol. 30, no. 1, 2016.
[33] M. Kushiyama, Y. Shimazaki, M. Murakami, and Y. Yamashita, "Relationship between intake of green tea and periodontal disease," Journal of Periodontology, vol. 80, no. 3, pp. 372-377, 2009.

[34] B. Narotzki, Y. Levy, D. Aizenbud, and A. Z. Reznick, "Green tea and its major polyphenol EGCG increase the activity of oral peroxidases," Advances in Experimental Medicine and Biology, vol. 756, pp. 99-104, 2013.

[35] J. Burana-osot and W. Yanpaisan, "Catechins and caffeine contents of green tea commercialized in Thailand," Journal of Pharmaceutical and Biomedical Sciences, vol. 22, no. 17, pp. 1-7, 2012.

[36] F. Hajiaghaalipour, J. Sanusi, and M. S. Kanthimathi, “Temperature and Time of Steeping Affect the Antioxidant Properties of White, Green, and Black Tea Infusions," Journal of Food Science, vol. 81, no. 1, pp. H246-H254, 2016.

[37] W.-Y. Han, J.-G. Huang, X. Li et al., "Altitudinal effects on the quality of green tea in east China: a climate change perspective," European Food Research and Technology, vol. 243, no. 2, pp. 323330, 2017.

[38] Z.-X. Han, M. M. Rana, G.-F. Liu et al., "Green tea flavour determinants and their changes over manufacturing processes," Food Chemistry, vol. 212, pp. 739-748, 2016.

[39] C. Lantano, M. Rinaldi, A. Cavazza, D. Barbanti, and C. Corradini, "Effects of alternative steeping methods on composition, antioxidant property and colour of green, black and oolong tea infusions," Journal of Food Science and Technology, vol. 52, no. 12, pp. 8276-8283, 2015.

[40] J.-E. Lee, B.-J. Lee, J.-O. Chung et al., "Geographical and Climatic Dependencies of Green Tea (Camellia sinensis) Metabolites: A 1H NMR-Based Metabolomics Study," Journal of Agricultural and Food Chemistry, vol. 58, no. 19, pp. 10582-10589, 2010.

[41] L.-S. Lee, S.-H. Kim, Y.-B. Kim, and Y.-C. Kim, "Quantitative analysis of major constituents in green tea with different plucking periods and their antioxidant activity," Molecules, vol. 19, no. 7, pp. 9173-9186, 2014.

[42] M. Liu, H. Tian, J. Wu et al., "Erratum: Relationship between gene expression and the accumulation of catechin during spring and autumn in tea plants (Camellia sinensis L.)," Horticulture Research, vol. 2, no. 1, 2015.

[43] M. McAlpine and W. Ward, "Influence of Steep Time on Polyphenol Content and Antioxidant Capacity of Black, Green, Rooibos, and Herbal Teas," Beverages, vol. 2, no. 3, p. 17, 2016.

[44] S. Sabhapondit, T. Karak, L. P. Bhuyan, B. C. Goswami, and M. Hazarika, "Diversity of catechin in Northeast Indian Tea cultivars," The Scientific World Journal, vol. 2012, Article ID 485193, 2012.

[45] S. Saklar, E. Ertas, I. S. Ozdemir, and B. Karadeniz, "Effects of different brewing conditions on catechin content and sensory acceptance in Turkish green tea infusions," Journal of Food Science and Technology, vol. 52, no. 10, pp. 6639-6646, 2015.

[46] H. Ashihara, W.-W. Deng, W. Mullen, and A. Crozier, "Distribution and biosynthesis of flavan-3-ols in Camellia sinensis seedlings and expression of genes encoding biosynthetic enzymes," Phytochemistry, vol. 71, no. 5-6, pp. 559-566, 2010.

[47] T. Atomssa and A. V. Cholap, "Characterization and determination of catechins in green tea leaves using UV-visible spectrometer," Journal of Engineering and Technology Research, vol. 7, no. 1, pp. 22-31, 2015. 
[48] K. A. Clarke, T. P. Dew, R. E. B. Watson et al., "High performance liquid chromatography tandem mass spectrometry dual extraction method for identification of green tea catechin metabolites excreted in human urine," Journal of Chromatography B, vol. 972, pp. 29-37, 2014.

[49] S. Saha, W. Hollands, P. W. Needs et al., "Human O-sulfated metabolites of (-)-epicatechin and methyl-(-)-epicatechin are poor substrates for commercial aryl-sulfatases: Implications for studies concerned with quantifying epicatechin bioavailability," Pharmacological Research, vol. 65, no. 6, pp. 592-602, 2012.

[50] A. Zinellu, S. Sotgia, B. Scanu et al., "Human serum albumin increases the stability of green tea catechins in aqueous physiological conditions," PLoS ONE, vol. 10, no. 7, Article ID e0134690, 2015.

[51] M. N. Clifford, J. J. van der Hooft, and A. Crozier, "Human studies on the absorption, distribution, metabolism, and excretion of tea polyphenols," American Journal of Clinical Nutrition, vol. 98, no. 6, pp. 1619S-1630S, 2013.

[52] M. Renouf, C. Marmet, P. A. Guy et al., "Dose-response plasma appearance of green tea catechins in adults," Molecular Nutrition \& Food Research, vol. 57, no. 5, pp. 833-839, 2013.

[53] W. C. Reygaert, "The antimicrobial possibilities of green tea, Frontiers in Microbiology, vol. 5, article 434, 2014.

[54] H. H. Chow, Y. Cai, D. S. Alberts et al., "Phase I pharmacokinetic study of tea polyphenols following single-dose administration of epigallocatechin gallate and polyphenon E," Cancer Epidemiology, Biomarkers \& Prevention, vol. 10, no. 1, pp. 53-58, 2001.

[55] H.-H. S. Chow, Y. Cai, I. A. Hakim et al., "Pharmacokinetics and safety of green tea polyphenols after multiple-dose administration of epigallocatechin gallate and polyphenon $\mathrm{E}$ in healthy individuals," Clinical Cancer Research, vol. 9, no. 9, pp. 33123319, 2003.

[56] M. J. Lee, Z. Y. Wang, and H. Li, "Analysis of plasma and urinary tea polyphenols in human subjects," Cancer Epidemiology, Biomarkers \& Prevention, vol. 4, no. 4, pp. 393-399, 1995.

[57] M. J. Lee, P. Maliakal, L. Chen et al., "Pharmacokinetics of tea catechins after ingestion of green tea and (-)-epigallocatechin3-gallate by humans: formation of different metabolites and individual variability," Cancer Epidemiology, Biomarkers \& Prevention, vol. 11, no. 10, pp. 1025-1032, 2002.

[58] K. Nakagawa, S. Okuda, and T. Miyazawa, "Dose-dependent incorporation of tea catechins, (-)-epigallocatechin-3-gallate and (-)-epigallocatechin, into human plasma," Bioscience, Biotechnology, and Biochemistry, vol. 61, no. 12, pp. 1981-1985, 1997.

[59] U. Ullmann, J. Haller, J. P. Decourt et al., "A single ascending dose study of epigallocatechin gallate in healthy volunteers," Journal of International Medical Research, vol. 31, no. 2, pp. 88$101,2003$.

[60] U. Ullmann, J. Haller, J. D. Decourt, J. Girault, V. Spitzer, and P. Weber, "Plasma-kinetic characteristics of purified and isolated green tea catechin epigallocatechin gallate (EGCG) after 10 days repeated dosing in healthy volunteers," International Journal for Vitamin and Nutrition Research, vol. 74, no. 4, pp. 269-278, 2004.

[61] C. S. Yang, L. Chen, M. J. Lee, D. Balentine, M. C. Kuo, and S. P. Schantz, "Blood and urine levels of tea catechins after ingestion of different amounts of green tea by human volunteers," Cancer Epidemiology Biomarkers \& Prevention, vol. 7, no. 4, pp. 351-354, 1998.

[62] L. E. Rhodes, G. Darby, K. A. Massey et al., "Oral green tea catechin metabolites are incorporated into human skin and protect against UV radiation-induced cutaneous inflammation in association with reduced production of pro-inflammatory eicosanoid 12-hydroxyeicosatetraenoic acid," British Journal of Nutrition, vol. 110, no. 5, pp. 891-900, 2013.

[63] J. Jeon, J. H. Kim, and C. K. Lee, “The antimicrobial activity of (-)-epigallocatechin-3-gallate and green tea extracts against Pseudomonas aeruginosa and Escherichia coli isolated from skin wounds," Annals of Dermatology, vol. 26, no. 5, pp. 564$569,2014$.

[64] J. Steinmann, J. Buer, T. Pietschmann, and E. Steinmann, "Antiinfective properties of epigallocatechin-3-gallate (EGCG), a component of green tea," British Journal of Pharmacology, vol. 168, no. 5, pp. 1059-1073, 2013.

[65] M. Nakayama, K. Shimatani, T. Ozawa et al., "Mechanism for the antibacterial action of epigallocatechin gallate (EGCg) on Bacillus subtilis," Bioscience, Biotechnology, and Biochemistry, vol. 79, no. 5, pp. 845-854, 2015.

[66] A. Ben Lagha, B. Haas, and D. Grenier, "Tea polyphenols inhibit the growth and virulence properties of Fusobacterium nucleatum," Scientific Reports, vol. 7, 2017.

[67] K.-M. Lee, M. Yeo, J.-S. Choue et al., "Protective mechanism of epigallocatechin-3-gallate against Helicobocter pylori-induced gastric epithelial cytotoxicity via the blockage of TLR- 4 signaling," Helicobacter, vol. 9, no. 6, pp. 632-642, 2004.

[68] X. Xu, X. D. Zhou, and C. D. Wu, "The tea catechin epigallocatechin gallate suppresses cariogenic virulence factors of Streptococcus mutans," Antimicrobial Agents and Chemotherapy, vol. 55, no. 3, pp. 1229-1236, 2011.

[69] R. Kanagaratnam, R. Sheikh, F. Alharbi, and D. H. Kwon, "An efflux pump (MexAB-OprM) of Pseudomonas aeruginosa is associated with antibacterial activity of Epigallocatechin-3gallate (EGCG)," Phytomedicine, vol. 36, pp. 194-200, 2017.

[70] S. Lee, G. S. A. Razqan, and D. H. Kwon, "Antibacterial activity of epigallocatechin-3-gallate (EGCG) and its synergism with $\beta$-lactam antibiotics sensitizing carbapenem-associated multidrug resistant clinical isolates of Acinetobacter baumannii," Phytomedicine, vol. 24, pp. 49-55, 2017.

[71] H. Gradišar, P. Pristovšek, A. Plaper, and R. Jerala, "Green tea catechins inhibit bacterial DNA gyrase by interaction with its ATP binding site," Journal of Medicinal Chemistry, vol. 50, no. 2, pp. 264-271, 2007.

[72] C. Kohda, Y. Yanagawa, and T. Shimamura, "Epigallocatechin gallate inhibits intracellular survival of Listeria monocytogenes in macrophages," Biochemical and Biophysical Research Communications, vol. 365, no. 2, pp. 310-315, 2008.

[73] Y. Wang and S. Ma, "Recent advances in inhibitors of bacterial fatty acid synthesis type II (FASII) system enzymes as potential antibacterial agents," ChemMedChem, vol. 8, no. 10, pp. 15891608, 2013.

[74] L. G. Xiong, Y. J. Chen, J. W. Tong et al., “Tea polyphenol epigallocatechin gallate inhibits Escherichia coli by increasing endogenous oxidative stress," Food Chemistry, vol. 217, pp. 196204, 2017.

[75] Y. S. Cho, N. L. Schiller, H. Y. Kahng, and K. H. Oh, "Cellular responses and proteomic analysis of Escherichia coli exposed to green tea polyphenols," Current Microbiology, vol. 55, no. 6, pp. 501-506, 2007.

[76] T. W. Sirk, E. F. Brown, M. Friedman, and A. K. Sum, "Molecular binding of catechins to biomembranes: relationship to biological activity," Journal of Agricultural and Food Chemistry, vol. 57, no. 15 , pp. $6720-6728,2009$. 
[77] T. W. Sirk, E. F. Brown, A. K. Sum, and M. Friedman, "Molecular dynamics study on the biophysical interactions of seven green tea catechins with lipid bilayers of cell membranes," Journal of Agricultural and Food Chemistry, vol. 56, no. 17, pp. 7750-7758, 2008.

[78] O. Levinger, T. Bikels-Goshen, E. Landau, M. Fichman, and R. Shapira, "Epigallocatechin gallate induces upregulation of the two-component VraSR system by evoking a cell wall stress response in Staphylococcus aureus," Applied and Environmental Microbiology, vol. 78, no. 22, pp. 7954-7959, 2012.

[79] P. D. Stapleton, S. Shah, K. Ehlert, Y. Hara, and P. W. Taylor, "The $\beta$-lactam-resistance modifier (-)-epicatechin gallate alters the architecture of the cell wall of Staphylococcus aureas," Microbiology, vol. 153, no. 7, pp. 2093-2103, 2007.

[80] A. Sharma, S. Gupta, I. P. Sarethy, S. Dang, and R. Gabrani, "Green tea extract: Possible mechanism and antibacterial activity on skin pathogens," Food Chemistry, vol. 135, no. 2, pp. 672675, 2012.

[81] M. Stenvang, M. S. Dueholm, B. S. Vad et al., "Epigallocatechin gallate remodels overexpressed functional amyloids in pseudomonas aeruginosa and increases biofilm susceptibility to antibiotic treatment," The Journal of Biological Chemistry, vol. 291, no. 51, pp. 26540-26553, 2016.

[82] M. Spina, M. Cuccioloni, M. Mozzicafreddo et al., "Mechanism of inhibition of wt-dihydrofolate reductase from E. coli by tea epigallocatechin-gallate," Proteins: Structure, Function, and Genetics, vol. 72, no. 1, pp. 240-251, 2008.

[83] N. Chinnam, P. K. Dadi, S. A. Sabri, M. Ahmad, M. A. Kabir, and Z. Ahmad, "Dietary bioflavonoids inhibit Escherichia coli ATP synthase in a differential manner," International Journal of Biological Macromolecules, vol. 46, no. 5, pp. 478-486, 2010.

[84] W.-H. Zhao, Z.-Q. Hu, Y. Hara, and T. Shimamura, "Inhibition by epigallocatechin gallate (EGCg) of conjugative R plasmid transfer in Escherichia coli," Journal of Infection and Chemotherapy, vol. 7, no. 3, pp. 195-197, 2001.

[85] E. Aboulmagd, H. I. Al-Mohamme, and S. Al-Badry, "Synergism and Postantibiotic Effect of Green Tea Extract and Imipenem Against Methicillin-resistant Staphylococcus aureus," Journal of Microbiology, vol. 1, no. 3, pp. 89-96, 2011.

[86] J. Fournier-Larente, M.-P. Morin, and D. Grenier, "Green tea catechins potentiate the effect of antibiotics and modulate adherence and gene expression in Porphyromonas gingivalis," Archives of Oral Biolog, vol. 65, pp. 35-43, 2016.

[87] B. Haghjoo, L. H. Lee, U. Habiba, H. Tahir, M. Olabi, and T. Chu, "The synergistic effects of green tea polyphenols and antibiotics against potential pathogens," Advances in Bioscience and Biotechnology, vol. 04, no. 11, pp. 959-967, 2013.

[88] A. Noormandi and F. Dabaghzadeh, "Effects of green tea on Escherichia coli as a uropathogen," Journal of Traditional and Complementary Medicine, vol. 5, no. 1, pp. 15-20, 2015.

[89] D. N. Passat, "Interactions of Black and Green Tea Water Extracts with Antibiotics Activity in Local Urinary Isolated Escherichia coli," Journal of Al-Nahrain University Science, vol. 15, no. 3, pp. 134-142, 2012.

[90] R. C. Fink, B. Roschek Jr., and R. S. Alberte, "HIV type-1 entry inhibitors with a new mode of action," Antiviral Chemistry \& Chemotherapy, vol. 19, no. 6, pp. 243-255, 2009.

[91] I. Hauber, H. Hohenberg, B. Holstermann, W. Hunstein, and J. Hauber, "The main green tea polyphenol epigallocatechin3-gallate counteracts semen-mediated enhancement of HIV infection," Proceedings of the National Acadamy of Sciences of the United States of America, vol. 106, no. 22, pp. 9033-9038, 2009.
[92] Y. Lin, Y. Wu, C. Tseng et al., "Green Tea Phenolic Epicatechins Inhibit Hepatitis C Virus Replication via Cycloxygenase-2 and Attenuate Virus-Induced Inflammation," PLoS ONE, vol. 8, no. 1, p. e54466, 2013.

[93] S. Liu, H. Li, L. Chen et al., “(-)-epigallocatechin-3-gallate inhibition of epstein-barr virus spontaneous lytic infection involves ERK1/2 and PI3-K/Akt signaling in EBV-positive cells," Carcinogenesis, vol. 34, no. 3, pp. 627-637, 2013.

[94] J.-Y. Pang, K.-J. Zhao, J.-B. Wang, Z.-J. Ma, and X.-H. Xiao, "Green tea polyphenol, epigallocatechin-3-gallate, possesses the antiviral activity necessary to fight against the hepatitis B virus replication in vitro," Journal of Zhejiang University SCIENCE B, vol. 15, no. 6, pp. 533-539, 2014.

[95] J. Yang, L. Li, S. Tan et al., "A natural theaflavins preparation inhibits HIV-1 infection by targeting the entry step: Potential applications for preventing HIV-1 infection," Fitoterapia, vol. 83, no. 2, pp. 348-355, 2012.

[96] J. Xu, Z. Xu, W. Zheng et al., "A review of the antiviral role of green tea catechins," Molecules, vol. 22, no. 8, Article ID 1337, 2017.

[97] K. Matsumoto, H. Yamada, N. Takuma, H. Niino, and Y. M. Sagesaka, "Effects of green tea catechins and theanine on preventing influenza infection among healthcare workers: a randomized controlled trial," BMC Complementary and Alternative Medicine, vol. 11, no. 15, 2011.

[98] M. Aboulaila, N. Yokoyama, and I. Igarashi, "Inhibitory effects of (-)-Epigallocatechin-3-gallate from green tea on the growth of Babesia parasites," Parasitology, vol. 137, no. 5, pp. 785-791, 2010.

[99] M. C. Güida, M. I. Esteva, A. Camino, M. M. Flawiá, H. N. Torres, and C. Paveto, "Trypanosoma cruzi: in vitro and in vivo antiproliferative effects of epigallocatechin gallate (EGCg)," Experimental Parasitology emphasizes, vol. 117, no. 2, pp. 188194, 2007.

[100] J. D. F. Inacio, L. Gervazoni, M. M. Canto-Cavalheiro, and E. E. Almeida-Amaral, "The Effect of (-)-Epigallocatechin 3O - Gallate In Vitro and In Vivo in Leishmania braziliensis: Involvement of Reactive Oxygen Species as a Mechanism of Action," PLOS Neglected Tropical Diseases, vol. 8, no. 8, Article ID e3093, 2014.

[101] P. Thipubon, C. Uthaipibull, S. Kamchonwongpaisan, W. Tipsuwan, and S. Srichairatanakool, "Inhibitory effect of novel iron chelator, 1-(N-acetyl-6-aminohexyl)-3-hydroxy-2methylpyridin-4-one (CM1) and green tea extract on growth of Plasmodium falciparum," Malaria Journal, vol. 14, no. 1, article no. 382, 2015.

[102] P. A. Vigueira, S. S. Ray, B. A. Martin, M. M. Ligon, and K. S. Paul, "Effects of the green tea catechin (-)-epigallocatechin gallate on Trypanosoma brucei," International Journal for Parasitology: Drugs and Drug Resistance, vol. 2, pp. 225-229, 2012.

[103] C. R. Da Silva, J. B. De Andrade Neto, R. De Sousa Campos et al., "Synergistic effect of the flavonoid catechin, quercetin, or epigallocatechin gallate with fluconazole induces apoptosis in Candida tropicalis resistant to fluconazole," Antimicrobial Agents and Chemotherapy, vol. 58, no. 3, pp. 1468-1478, 2014.

[104] M. Muthu, J. Gopal, S. X. Min, and S. Chun, "Green Tea Versus Traditional Korean Teas: Antibacterial/Antifungal or Both?" Applied Biochemistry and Biotechnology, vol. 180, no. 4, pp. 780790, 2016.

[105] Y. Ning, J. Ling, and C. D. Wu, "Synergistic effects of tea catechin epigallocatechin gallate and antimycotics against oral Candida 
species," Archives of Oral Biolog, vol. 60, no. 10, pp. 1565-1570, 2015.

[106] B. J. Park, H. Taguchi, K. Kamei, T. Matsuzawa, S.-H. Hyon, and J.-C. Park, "In vitro antifungal activity of epigallocatechin 3-O-gallate against clinical isolates of dermatophytes," Yonsei Medical Journal, vol. 52, no. 3, pp. 535-538, 2011.

[107] A. Thomas, S. Thakur, R. Habib, and N. Marwah, "Comparison of Antimicrobial Efficacy of Green Tea, Garlic with Lime, and Sodium Fluoride Mouth Rinses against Streptococcus mutans, Lactobacilli species, and Candida albicans in Children: A Randomized Double-blind Controlled Clinical Trial," International Journal of Clinical Pediatric Dentistry, vol. 10, no. 3, pp. 234-239, 2017.

[108] B. E. Roberts, M. L. Duennwald, H. Wang et al., "A synergistic small-molecule combination directly eradicates diverse prion strain structures," Nature Chemical Biology, vol. 5, no. 12, pp. 936-946, 2009.

[109] A. Farooqui, A. Khan, I. Borghetto, S. U. Kazmi, S. Rubino, and B. Paglietti, "Synergistic antimicrobial activity of Camellia sinensis and Juglans regia against multidrug-resistant bacteria," PLoS ONE, vol. 10, no. 2, Article ID e0118431, 2015.

[110] C. A. Rowe, M. P. Nantz, J. F. Bukowski, and S. S. Percival, "Specific formulation of Camellia sinensis prevents cold and flu symptoms and enhances gamma, delta $\mathrm{T}$ cell function: a randomized, double-blind, placebo-controlled study," Journal of the American College of Nutrition, vol. 26, no. 5, pp. 445-452, 2007.

[111] M. Park, H. Yamada, K. Matsushita et al., "Green tea consumption is inversely associated with the incidence of influenza infection among schoolchildren in a tea plantation area of Japan," Journal of Nutrition, vol. 141, no. 10, pp. 1862-1870, 2011.

[112] T. Noda, T. Ojima, S. Hayasaka, C. Murata, and A. Hagihara, "Gargling for oral hygiene and the development of fever in childhood: A population study in Japan," Journal of Epidemiology, vol. 22, no. 1, pp. 45-49, 2012.

[113] H. Yamada, N. Takuma, T. Daimon, and Y. Hara, "Gargling with tea catechin extracts for the prevention of influenza infection in elderly nursing home residents: a prospective clinical study," The Journal of Alternative and Complementary Medicine, vol. 12, no. 7, pp. 669-672, 2006.

[114] H. Yamada, T. Daimon, K. Matsuda et al., "A randomized controlled study on the effects of gargling with tea catechin extracts on the prevention of influenza in healthy adults," Japanese Journal of Clinical Pharmacology and Therapeutics, vol. 38, no. 5, pp. 323-330, 2007. 


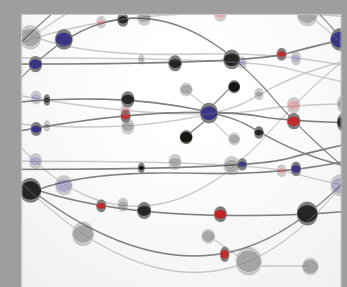

The Scientific World Journal
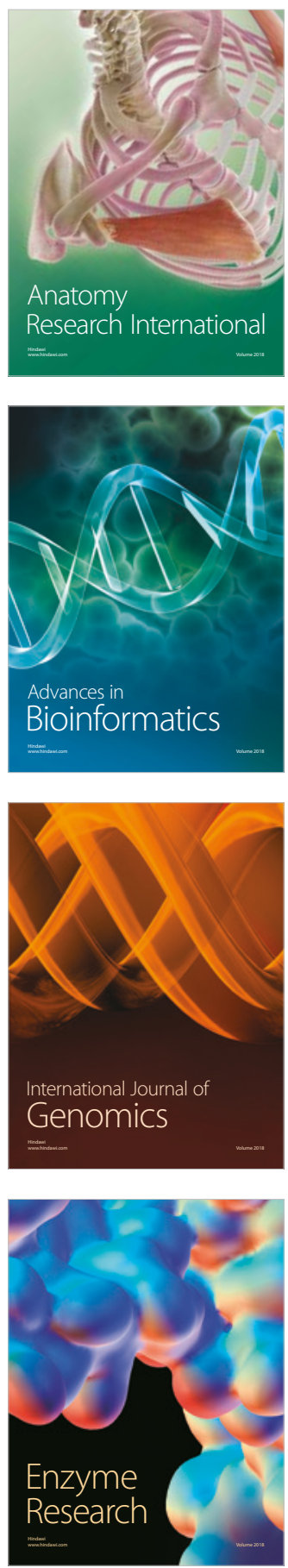
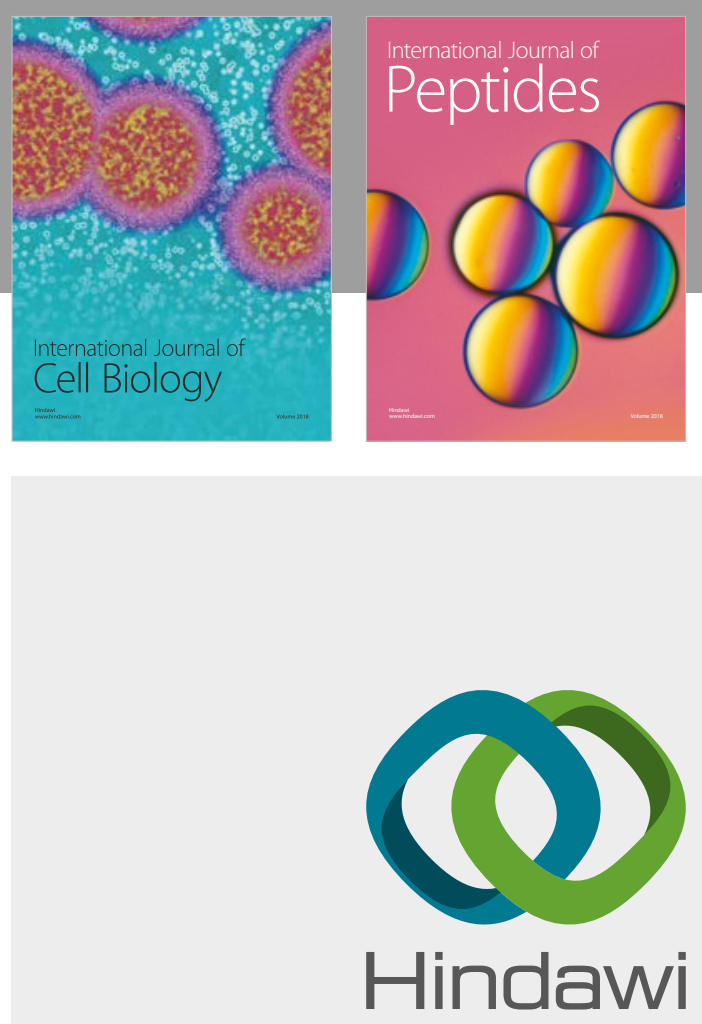

Submit your manuscripts at

www.hindawi.com
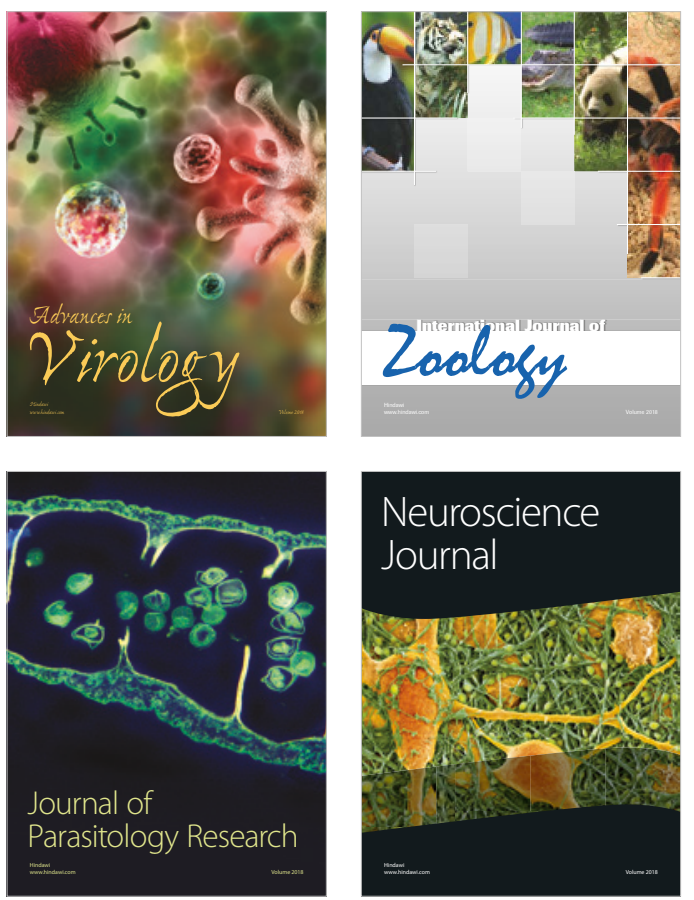
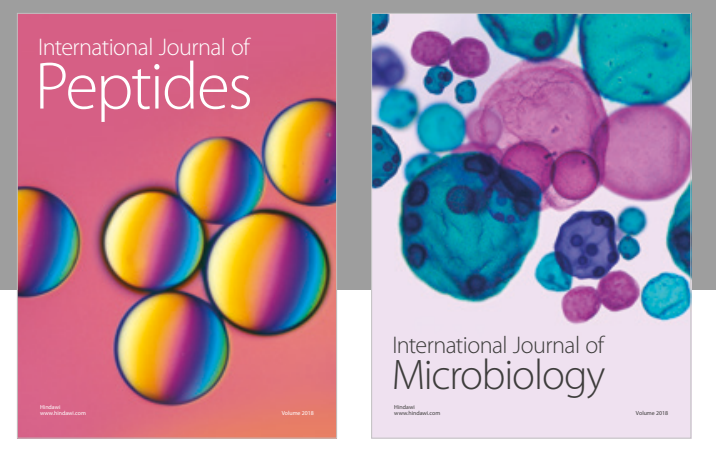

nternational Journal of Microbiology
Journal of
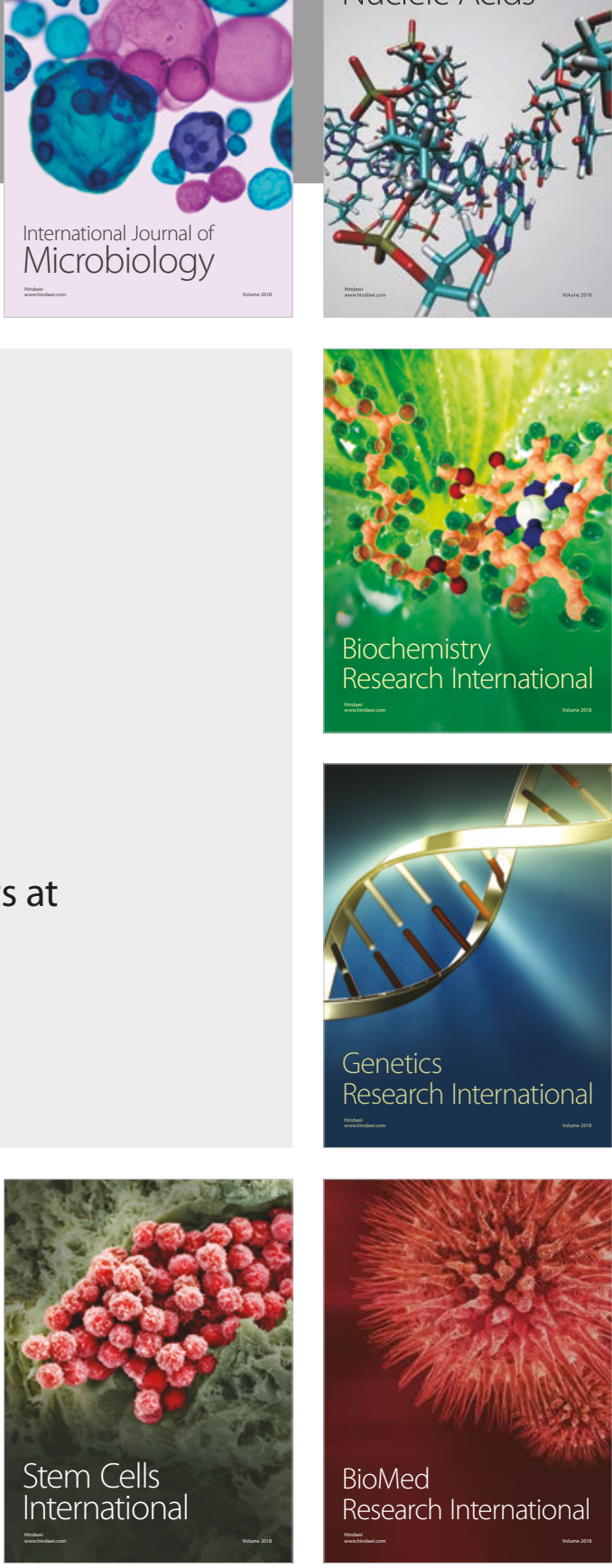
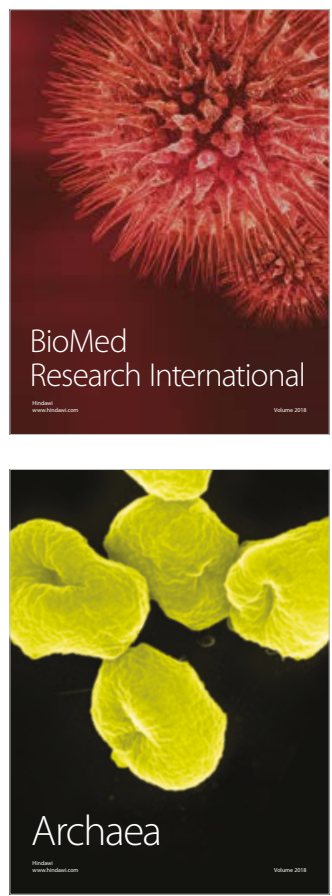